\title{
AN EXPERIMENTAL STUDY OF AEROSPACE MATERIAL DURING FABRICATION OF V GROOVE USING WEDM
}

\author{
ASHISH GOYAL ${ }^{1}$, ANAND PANDEY ${ }^{2} \&$ POOJA SHARMA ${ }^{3}$ \\ ${ }^{1,2}$ Department of Mechanical Engineering, Manipal University, Jaipur, Rajasthan, India \\ ${ }^{3}$ Department of Computer Science, Manipal University, Jaipur, Rajasthan, India
}

\begin{abstract}
In this experimental study, the machining parameters, tool electrode, current, pulse on time, pulse of time, wire feed and wire tension has been studied using Inconel-625 as work piece in Wire electrical discharge machining (WEDM). The optimization of these parameters is very crucial for the greatest manufacturing results and production at the lowest cost. In order to get the maximum output from these industries, the material removal rate and surface roughness should be optimized. The experiment has been executed using Taguchi's mixed array L18 $\left(2^{1 * 3^{5}}\right)$ and ANOVA technique using MINITAB software to determine the significant and non-significant parameters. This paper demonstrates that the WEDM process parameters can be adjusted for the achievement of better MRR and SR simultaneously.

KEYWORDS: WEDM, Cryogenic, Inconel-625, Taguchi, MRR \& SR
\end{abstract}

Received: Apr 17, 2017; Accepted: May 15, 2017; Published: Jun 06, 2017; Paper Id.: IJMPERDJUN201726

\section{INTRODUCTION}

In industries now days, the production of complex structures has become challenging. In order to achieve these requirements the non-conventional techniques are being used, one of them is WEDM. The non-conventional technique has the advantages of improving the tool life, perform accurate and precise machining operations and produce less noise. The advancement of technology requires more advanced material to fulfil the needs. Inconel 625 is a super alloy which possesses high strength, resistance to elevated temperatures, protection against corrosion and oxidation. This advanced material is useful in shipping, automotive components manufacturing, defence industries, etc. Investigation has been done for improving the tool life using cryogenic cooling. The tool had been modified to apply liquid nitrogen directly to the machining zone. The application of the cryogenic cooling, was found to be more effective at higher cutting speed and for static mechanical properties [1-2]. Investigation of machining performance of cryogenically treated electrodes in electric discharge machining was carried out. From the study, it was observed that there is a significant reduction in tool wear rate of cryogenic treated tool electrode [3-4]. Yildiz et al. investigated the effect of cold and cryogenic treatments on the machinability of Berylliumcopper alloy. The Beryllium-copper alloy was treated to a round $-150^{\circ} \mathrm{F}$ and for cold treatment around $-300^{\circ} \mathrm{F}$. From the experimental results, it was concluded that 20-30\% increment was there in MRR of cold and cryogenic treated work pieces [5]. Shane Y. Hong et al. reported new approaches for improvement of tool life which is the major constraint of economical point of view for industry. This approach uses a minimum amount of liquid nitrogen injected through a micro-nozzle formed between the chip preacher and the tool rake and assisted by the necessary nozzle for flank cooling. By experiments, it was proved that the cryogenic process improved tool life by other heat treatment process [6]. The comparisonbetweenthe performance of sintered $\mathrm{Cu}$-Tic electrode tip and 
conventional copper electrode tip was analysed in ultra-sonic assisted cryogenically cooled electrical discharge machining (UACEDM). It was found that the electrode wear ratio, surface roughness and out of roundness to be lower in UACEDM than conventional electrode. [7]. Vinod et al. conducted an experiment to study the performance of aluminium, silicon carbide material under conventional electrode and cryogenically cooled electrode. The electrode was modified so that it allowed liquid nitrogen to flow from the lower part to the upper part. Taguchi L18 mixed orthogonal array was used for experimental investigation. It was combined with grey relational analysis for optimization of the process parameters of EW, MRR and SR. Analysis of variance (ANOVA) were performed to determine the optimal parameter level. It was concluded that average surface was improved in liquid nitrogen cooling of the electrode [8]. Experimental study has been done to investigate the influence of process parameters for MRR, SR, Kerf, over cut and corner accuracy by machining of advanced materials by using Taguchi and ANOVA method [9-12].

\section{EXPERIMENTAL WORK}

The experimental work was performed on WEDM (Electronica spring cut 734) electronica machine tools Ltd. The WEDM machining set-up shown in Figure 1.

\section{Work Piece and Tool Material}

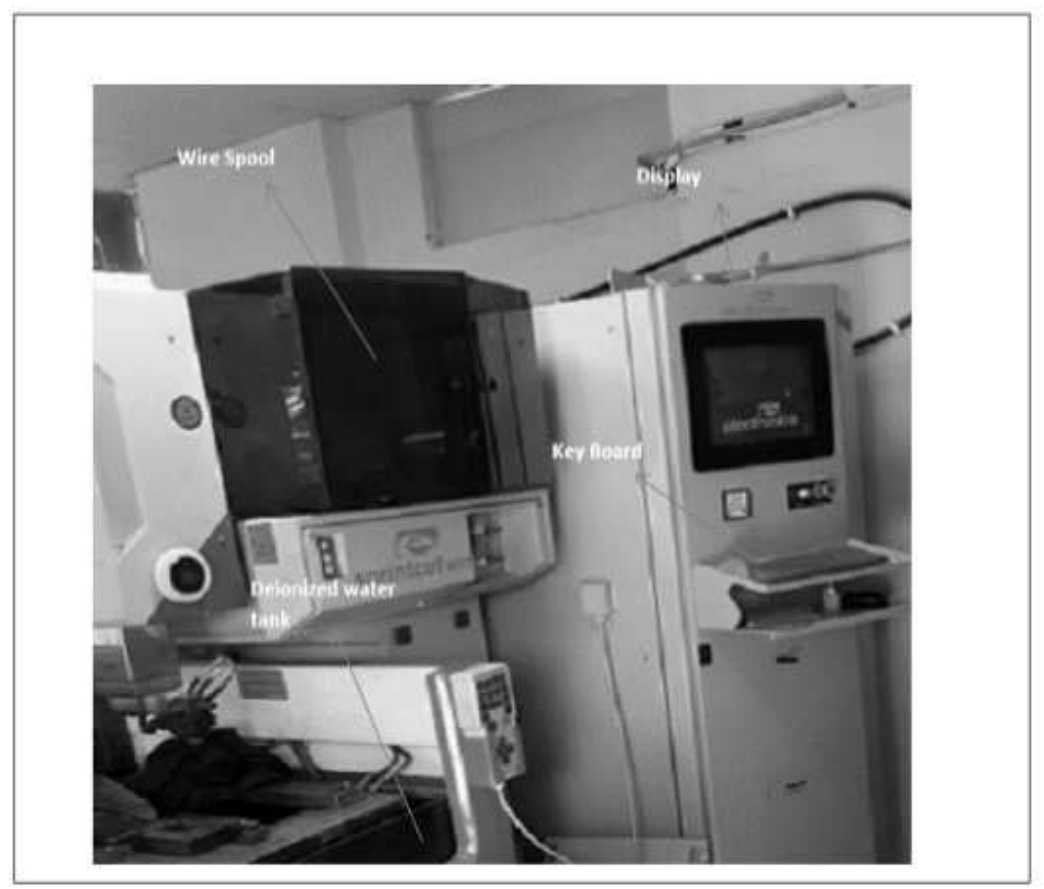

Figure 1: WEDM Machining Setup

The Inconel 625 has been used as a work piece material in the experimental work. Inconel 625 is a nickel-based super alloy that possesses high strength properties and resistance to higher temperatures. It also reveals remarkable protection against corrosion and oxidation. Its capability to withstand high stress and a wide range of temperatures, both in and out of water, as well as being competent to resist erosion while being exposed to highly acidic atmospheres makes it a suitablefor nuclear and marine applications. For current experimental work, the size of the work piece is $150 * 100 \mathrm{~mm}$ and thickness of the work piece is $3 \mathrm{~mm}$. Table 1 shows the chemical structure of Inconel 625 . 
Table 1: Chemical Structure of Inconel 625

\begin{tabular}{|c|c|c|c|c|c|c|c|c|c|c|}
\hline $\mathbf{N i}$ & $\mathbf{C r}$ & $\mathbf{F e}$ & $\mathbf{C o}$ & $\mathbf{M o}$ & $\mathbf{N b}$ & $\mathbf{T i}$ & $\mathbf{A l}$ & $\mathbf{C}$ & $\mathbf{M n}$ & $\mathbf{S i}$ \\
\hline $58(\mathrm{~min})$ & $20-23$ & 5 & 1 & $8-10$ & $3.2-4.2$ & 0.4 & 0.4 & 0.1 & 0.5 & 0.5 \\
\hline
\end{tabular}

Zinc coated wire (plain and cryogenic) has been used as a tool electrode for an experimental work. The diameter of the tool electrode was $0.25 \mathrm{~mm}$. Zinc metal has various features that make it a compatible corrosion protective coating for ferrous and nonferrous material. Zinc's superb corrosion resistance in most environments is for its effective use as a curing coating on a variety of products. The applications are galvanization, mechanical painting, zinc rich paints, sherardizing and electro galvanizing.

\section{CRYOGENIC TREATMENT}

In the current study, plain zinc coated wire and cryogenic treated zinc coated wire were considered as tool electrode. Cryogenic treatment is a process, in which the work piece is treated below $-190^{\circ} \mathrm{C}$ to $-200^{\circ} \mathrm{C}(\mathrm{cryogenic}$ temperature). This helps in eliminating the residual stressesand helps in improving the mechanical properties such as improved wear resistance, electrical and thermal properties, and dimensional stability. It also expands the metallurgical properties, such as increase carbide formation and amount of retained austenite is reduced. Figure 2 shows the cryogenic process cycle and table 2 represent the processes of cryogenic cycle.

Table 2

\begin{tabular}{|l|l|}
\hline A-B & Ramp Down \\
\hline B-C & Soaking \\
\hline C-D & Ramp up \\
\hline D-E & Temper Ramp Up \\
\hline E-F & Temper hold \\
\hline
\end{tabular}

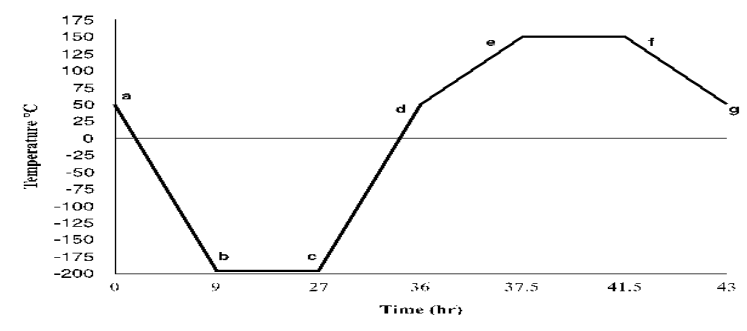

Figure 2: Cryogenic Process Cycle

\section{Methodology for Work}

In the present work, the Taguchi methodology has been used to design the investigators and study has been done by ANOVA. The experimentations were performed based on mixed orthogonal array L18 $\left(2^{1} * 3^{5}\right)$. A total of 18 experiments were performed. For current experimental design, control factors and their levels are shown in table 3 . The $\mathrm{V}$ groove profile has been fabricated in current experimental work as shown in Figure 3. The experiments were executed on electronic spring cuts 734 WEDM by taking Inconel 625 as a work material and the zinc coated wire (plain and cryogenic) as a tool electrode material. The flow chart of work is shown in Figure 4. 


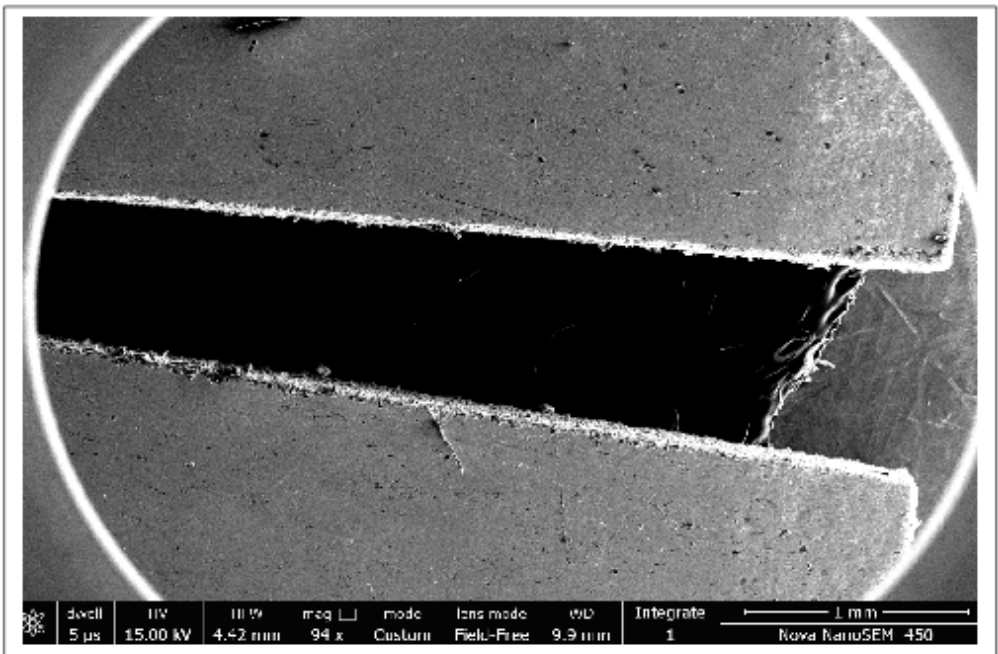

Figure 3: Fabricated V Groove Profile

\section{Experimental Design}

In the Taguchi method, two different methods are used to carry out the complete analysis. First, being standard approach, where, the results of a single run are processed through ANOVA analysis. The second method, which Taguchi strongly recommends for multiple runs, is to use the $\mathrm{S} / \mathrm{N}$ ratio for the same steps in the analysis. The $\mathrm{S} / \mathrm{N}$ ratio is a simultaneous quality metric, linked to the loss function. To study the comparative influence of machining parameters on response parameters, the analysis of $\mathrm{S} / \mathrm{N}$ ratio and ANOVA were carried out. The $\mathrm{S} / \mathrm{N}$ ratio features can be divided in the three categories, "larger is better", "smaller is better", "normal is better". For MRR, six process parameters were selected for "larger is better" and for SR, "smaller is better" were selected for obtaining the optimum machining parameters. According to the DOE (design of experiments), the respective $\mathrm{S} / \mathrm{N}$ ratio was tabulated with respect to different outputs.

Larger is better

$(\mathrm{S} / \mathrm{N})_{\mathrm{HB}}=-10 \log \left(\mathrm{MSD}_{\mathrm{HB}}\right)$

Smaller is better

$(\mathrm{s} / \mathrm{N})_{\mathrm{LB}}=-10 \log \left(\mathrm{MSD}_{\mathrm{LB}}\right)$ 


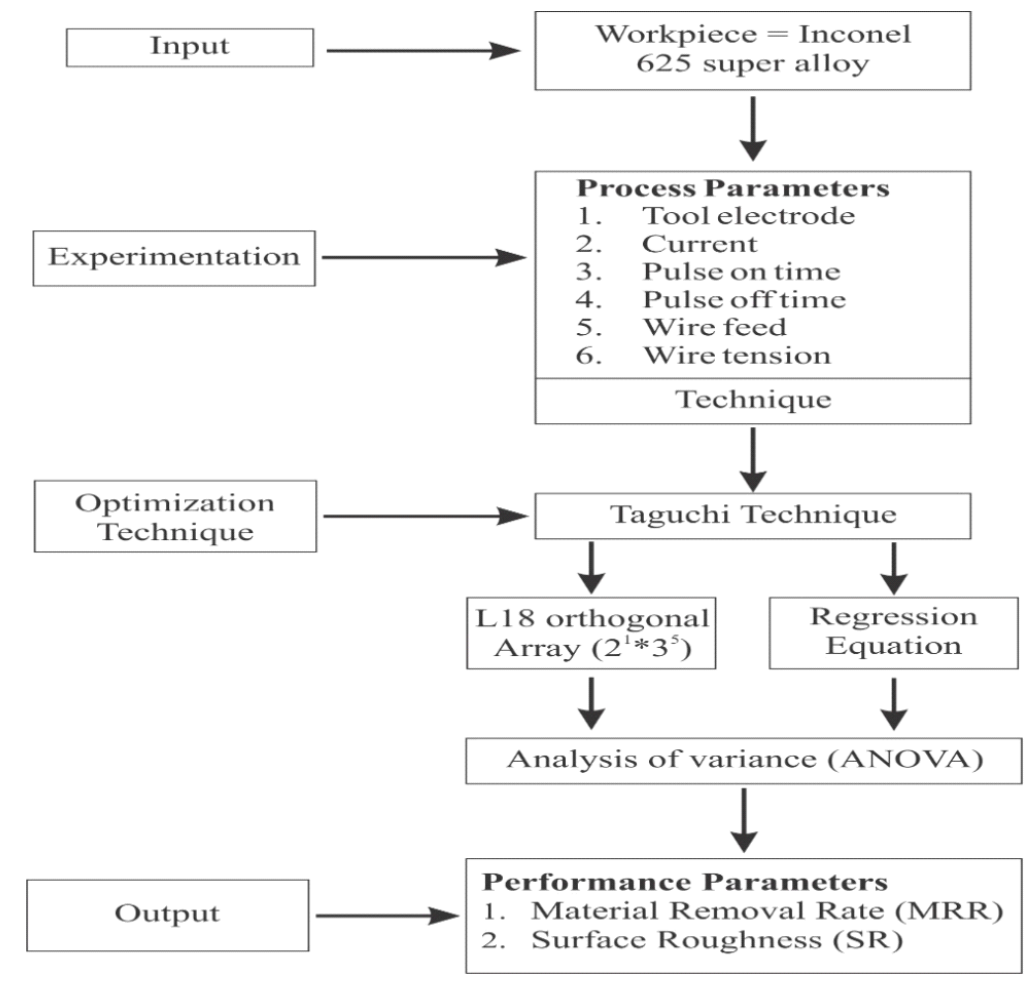

Figure 4: Flow Chart of Experiment Work

Table 3: Control Factor and Their Levels

\begin{tabular}{|l|l|l|c|c|c|}
\hline Symbol & Control Factor & Unit & Level1 & Level2 & Level3 \\
\hline A & Tool electrode & ---- & plain wire & Cryo- treated & - \\
\hline B & $\begin{array}{l}\text { Current } \\
\text { Intensity }\end{array}$ & $\mathrm{A}$ & 10 & 12 & 14 \\
\hline C & Pulse on time & $\mu \mathrm{s}$ & 105 & 115 & 125 \\
\hline $\mathrm{D}$ & Pulse off time & $\mu \mathrm{s}$ & 48 & 54 & 60 \\
\hline E & Wire feed & $\mathrm{m} / \mathrm{min}$. & 4 & 6 & 8 \\
\hline F & Wire tension & $\mathrm{N}$ & 7 & 9 & 11 \\
\hline
\end{tabular}

\section{RESULTS AND DISCUSSIONS}

\section{For MRR}

The results obtained from the Taguchi method are plotted in the Figure 5. From the figure, it can be observed that the MRR increases as increase current intensity. This may be due to reason that, high conductivity wire gives more energy to the processes additional to energy promoter and more electron emission. The temperature of the wire drops due to less resistance. Now from the table, we also observe that MRR increases as we increase the pulse of time and wire feed. The wire tension does not have any significant effect on MRR $(13,15)$.

Table 4: L18 $\left(2^{1 * 3^{5}}\right)$ OA, Experimental Results and Their Multi Response S/N Ratio (MRR)

\begin{tabular}{|c|c|c|c|c|c|c|c|c|c|c|c|}
\hline \multirow[b]{2}{*}{ S.No. } & \multicolumn{6}{|c|}{ Process Parameters } & \multicolumn{3}{|c|}{ MRR } & \multirow[b]{2}{*}{ MRR } & \multirow[t]{2}{*}{$\mathbf{S} / \mathbf{N}$} \\
\hline & $\begin{array}{c}\text { Tool } \\
\text { Electrode }\end{array}$ & $\begin{array}{c}\text { Current } \\
\text { (amp) }\end{array}$ & $\begin{array}{l}\text { Ton } \\
(\mu s)\end{array}$ & $\begin{array}{l}\text { Toff } \\
(\mu s)\end{array}$ & $\begin{array}{l}\text { WF } \\
(\mathrm{m} / \\
\text { min })\end{array}$ & $\begin{array}{l}\text { WT } \\
(\mathbf{N})\end{array}$ & 1 & 2 & 3 & & \\
\hline 1. & Plain & 10 & 105 & 48 & 4 & 7 & 3.14 & 2.73 & 3.62 & 3.16 & 10.00 \\
\hline 2. & Plain & 10 & 115 & 54 & 6 & 9 & 2.87 & 3.89 & 3.35 & 3.37 & 10.55 \\
\hline 3. & Plain & 10 & 125 & 60 & 8 & 11 & 3.87 & 3.51 & 2.88 & 3.42 & 10.68 \\
\hline
\end{tabular}




\begin{tabular}{|c|l|c|c|c|c|c|c|c|c|c|c|}
\hline 4. & Plain & 12 & 105 & 48 & 6 & 9 & 2.83 & 3.39 & 3.45 & 3.22 & 10.16 \\
\hline 5. & Plain & 12 & 115 & 54 & 8 & 11 & 3.39 & 3.97 & 3.43 & 3.59 & 11.11 \\
\hline 6. & Plain & 12 & 125 & 60 & 4 & 7 & 4.17 & 3.43 & 3.59 & 3.73 & 11.43 \\
\hline 7. & Plain & 14 & 105 & 54 & 4 & 11 & 3.59 & 2.68 & 2.83 & 3.03 & 9.63 \\
\hline 8. & Plain & 14 & 115 & 60 & 2 & 7 & 3.93 & 3.17 & 3.33 & 3.47 & 10.82 \\
\hline 9. & Plain & 14 & 125 & 48 & 8 & 9 & 4.57 & 3.69 & 3.17 & 3.81 & 11.61 \\
\hline 10. & Cryogenic & 10 & 105 & 60 & 8 & 9 & 2.95 & 2.99 & 3.71 & 3.21 & 10.14 \\
\hline 11. & Cryogenic & 10 & 115 & 48 & 4 & 11 & 3.91 & 3.02 & 3.63 & 3.52 & 10.93 \\
\hline 12. & Cryogenic & 10 & 125 & 54 & 6 & 7 & 2.94 & 2.82 & 3.99 & 3.25 & 10.23 \\
\hline 13. & Cryogenic & 12 & 105 & 54 & 8 & 7 & 3.58 & 3.96 & 3.41 & 3.65 & 11.24 \\
\hline 14. & Cryogenic & 12 & 115 & 60 & 4 & 9 & 2.94 & 3.44 & 3.84 & 3.40 & 10.64 \\
\hline 15. & Cryogenic & 12 & 125 & 48 & 6 & 11 & 3.15 & 3.99 & 3.55 & 3.56 & 11.03 \\
\hline 16. & Cryogenic & 14 & 105 & 60 & 6 & 11 & 4.12 & 3.73 & 3.83 & 3.89 & 11.80 \\
\hline 17. & Cryogenic & 14 & 115 & 48 & 8 & 7 & 4.51 & 3.91 & 3.81 & 4.07 & 12.20 \\
\hline 18. & Cryogenic & 14 & 125 & 54 & 4 & 9 & 3.43 & 3.82 & 3.68 & 3.64 & 11.22 \\
\hline
\end{tabular}

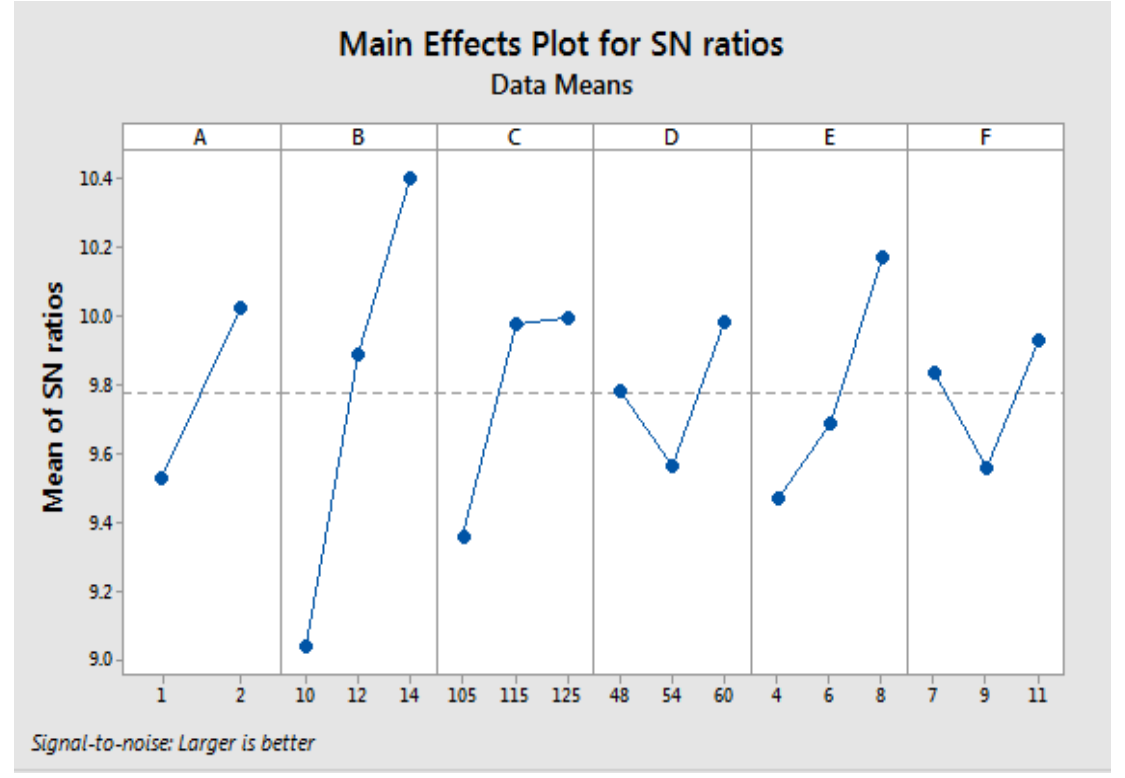

Figure 5: S/N Ratios Plot for MRR

Table 5: Response for Signal to Noise Ratio (MRR)

\begin{tabular}{|l|c|c|c|c|c|c|}
\hline Level & $\begin{array}{c}\text { Tool } \\
\text { Electrode }\end{array}$ & Current & $\begin{array}{c}\text { Pulse on } \\
\text { Time }\end{array}$ & $\begin{array}{c}\text { Pulse off } \\
\text { Time }\end{array}$ & $\begin{array}{c}\text { Wire } \\
\text { Feed }\end{array}$ & $\begin{array}{c}\text { Wire } \\
\text { Tension }\end{array}$ \\
\hline 1 & 10.67 & 10.43 & 10.50 & 10.99 & 10.65 & 10.99 \\
\hline 2 & 11.05 & 10.94 & 11.05 & 10.67 & 10.77 & 10.73 \\
\hline 3 & & 11.22 & 11.04 & 10.92 & 11.17 & 10.87 \\
\hline Delta & 0.38 & 0.80 & 0.54 & 0.32 & 0.52 & 0.26 \\
\hline Rank & 4 & 1 & 2 & 5 & 3 & 6 \\
\hline
\end{tabular}

Table 5 shows the response table for signal to noise ratio, gives the information of the rankings according to the most significant parameters. It was observed that current is the most significant value, followed by Ton, wire feed, tool electrode, pulse of time and wire tension. Table 6 shows the calculated P-values of the ANOVA to find out the significances of the parameters in WEDM for $\mathrm{V}$ groove profile. The values of ' $\mathrm{P}$ ', less than 0.05 indicate that these parameters have exposed major effect during the experiments. 
Table 6: Analysis of Variance (ANOVA) for MRR

\begin{tabular}{|l|c|c|c|c|c|}
\hline \multicolumn{1}{|c|}{ Source } & DF & Adj SS & AdjMS & F-value & P-Value \\
\hline Wire & 1 & 0.10837 & 0.108371 & 2.12 & 0.173 \\
\hline Current & 2 & 0.33111 & 0.331115 & 6.49 & 0.027 \\
\hline Ton & 2 & 0.12745 & 0.127445 & 2.50 & 0.142 \\
\hline Toff & 2 & 0.00379 & 0.003793 & 0.07 & 0.790 \\
\hline Wire Feed & 2 & 0.13512 & 0.135115 & 2.65 & 0.132 \\
\hline Wire tension & 2 & 0.00853 & 0.008533 & 0.17 & 0.691 \\
\hline Error & 11 & 0.56158 & 0.051053 & & \\
\hline \multicolumn{1}{|c|}{ Total } & $\mathbf{2 2}$ & $\mathbf{1 . 2 7 5 9 5}$ & & & \\
\hline \multicolumn{2}{|l}{} \\
\hline
\end{tabular}

\section{For SR}

The $\mathrm{S} / \mathrm{N}$ ratios of the experimental results are given in the response table 7. Figure 6 represents the main effect plot showing the effect of process parameters on the response of SR. Surface roughness initially, increase and then decreases with an increase in current. This happens because of each spark during cutting process a tiny volume of material is vaporized, which leave a cavity on work surface. The smoothness of machined surface depends on the depth of the cavity produced during a series of spark. The depth and size of this cavity depend on the intensity of the spark and the intensity of spark depends on current. Hence, we increase the current the surface roughness gradually decrease. [14]

Table 7: L18 $\left(2^{1} * 3^{5}\right)$ OA, Experimental Results and Their Multi Response S/N Ratio forSR

\begin{tabular}{|c|c|c|c|c|c|c|c|c|c|c|c|}
\hline \multirow[b]{2}{*}{ S. No. } & \multicolumn{6}{|c|}{ Process Parameters } & \multicolumn{3}{|c|}{ SR } & \multirow[b]{2}{*}{ SR } & \multirow[t]{2}{*}{$\mathbf{S} / \mathbf{N}$} \\
\hline & $\begin{array}{c}\text { Tool } \\
\text { Electrode }\end{array}$ & $\begin{array}{c}\text { Current } \\
\text { (amp) }\end{array}$ & $\begin{array}{l}\text { Ton } \\
(\mu \mathrm{s})\end{array}$ & $\begin{array}{l}\text { Toff } \\
(\mu \mathrm{s})\end{array}$ & $\begin{array}{c}\text { WF } \\
(\mathrm{m} / \mathbf{m i n})\end{array}$ & WT & 1 & 2 & 3 & & \\
\hline 1. & Plain & 10 & 105 & 48 & 4 & 7 & 3.55 & 3.44 & 3.45 & 3.48 & -10.83 \\
\hline 2. & Plain & 10 & 115 & 54 & 6 & 9 & 3.56 & 3.61 & 3.64 & 3.60 & -11.13 \\
\hline 3. & Plain & 10 & 125 & 60 & 8 & 11 & 3.93 & 3.88 & 3.98 & 3.93 & -11.88 \\
\hline 4. & Plain & 12 & 105 & 48 & 6 & 9 & 3.93 & 3.43 & 3.57 & 3.64 & -11.23 \\
\hline 5. & Plain & 12 & 115 & 54 & 8 & 11 & 3.71 & 3.64 & 3.65 & 3.66 & -11.28 \\
\hline 6. & Plain & 12 & 125 & 60 & 4 & 7 & 3.28 & 3.31 & 3.41 & 3.33 & -10.45 \\
\hline 7. & Plain & 14 & 105 & 54 & 4 & 11 & 3.43 & 3.52 & 3.59 & 3.51 & -10.91 \\
\hline 8. & Plain & 14 & 115 & 60 & 2 & 7 & 3.17 & 3.22 & 3.25 & 3.21 & -10.13 \\
\hline 9. & Plain & 14 & 125 & 48 & 8 & 9 & 2.99 & 3.05 & 3.09 & 3.04 & -9.66 \\
\hline 10. & Cryogenic & 10 & 105 & 60 & 8 & 9 & 3.88 & 3.91 & 3.74 & 3.84 & -11.69 \\
\hline 11. & Cryogenic & 10 & 115 & 48 & 4 & 11 & 3.33 & 3.37 & 3.41 & 3.37 & -10.55 \\
\hline 12. & Cryogenic & 10 & 125 & 54 & 6 & 7 & 3.59 & 3.63 & 3.56 & 3.59 & -11.10 \\
\hline 13. & Cryogenic & 12 & 105 & 54 & 8 & 7 & 4.01 & 4.11 & 4.03 & 4.05 & -12.14 \\
\hline 14. & Cryogenic & 12 & 115 & 60 & 4 & 9 & 3.7 & 3.77 & 3.74 & 3.73 & -11.44 \\
\hline 15. & Cryogenic & 12 & 125 & 48 & 6 & 11 & 3.48 & 3.51 & 3.72 & 3.57 & -11.05 \\
\hline 16. & Cryogenic & 14 & 105 & 60 & 6 & 11 & 3.88 & 3.91 & 3.94 & 3.91 & -11.84 \\
\hline 17. & Cryogenic & 14 & 115 & 48 & 8 & 7 & 3.37 & 3.33 & 3.39 & 3.36 & -10.53 \\
\hline 18. & Cryogenic & 14 & 125 & 54 & 4 & 9 & 3.37 & 2.97 & 3.29 & 3.21 & -10.13 \\
\hline
\end{tabular}

Table 7 and 8 represent the response table for signal to noise ratio and ANOVA analysis, respectively for SR. In the analysis of variance (ANOVA) table, $\mathrm{P}$ value lower than 0.05 implies that the parameter is highly significant. From the table, it is inferred that current, pulse on time and pulse off time are most significant parameter. 


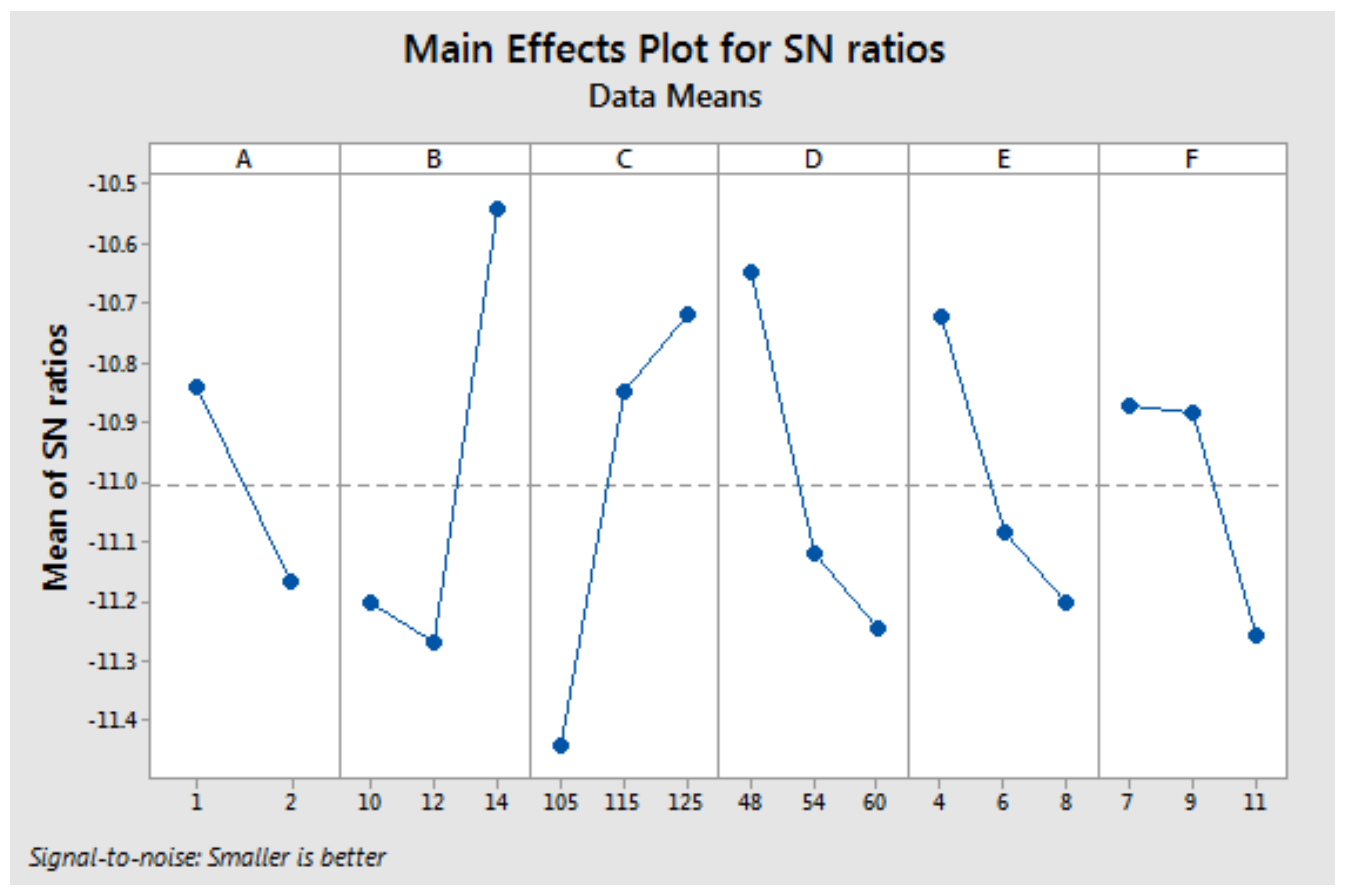

Figure 6: S/N Ratios for SR

Table 8: Response Table for Signal to Noise Ratios

\begin{tabular}{|l|c|c|c|c|c|c|}
\hline Level & $\begin{array}{c}\text { Tool } \\
\text { Electrode }\end{array}$ & Current & Ton & Toff & $\begin{array}{c}\text { Wire } \\
\text { Feed }\end{array}$ & $\begin{array}{c}\text { Wire } \\
\text { Tension }\end{array}$ \\
\hline 1 & -10.84 & -11.20 & -11.44 & -10.64 & -10.72 & -10.87 \\
\hline 2 & -11.17 & -11.27 & -10.85 & -11.12 & -11.09 & -10.88 \\
\hline 3 & & -10.54 & -10.72 & -11.25 & -11.20 & -11.26 \\
\hline Delta & 0.33 & 0.73 & 0.73 & 0.60 & 0.48 & 0.39 \\
\hline Rank & 6 & 1 & 2 & 3 & 4 & 5 \\
\hline
\end{tabular}

Table 9: Analysis of Variance (ANOVA) for SR

\begin{tabular}{|c|c|c|c|c|c|}
\hline Source & DF & Adj. SS & Adj. MS & F-Value & P-Value \\
\hline A & 1 & 0.08269 & 0.08269 & 2.66 & 0.131 \\
\hline B & 2 & 0.20454 & 0.20454 & 6.57 & 0.026 \\
\hline C & 2 & 0.25813 & 0.25813 & 8.30 & 0.015 \\
\hline D & 2 & 0.18667 & 0.18667 & 6.00 & 0.032 \\
\hline E & 2 & 0.13090 & 0.13090 & 4.21 & 0.065 \\
\hline F & 2 & 0.07156 & 0.07156 & 2.30 & 0.158 \\
\hline Error & 11 & 0.34226 & 0.03295 & & \\
\hline Total & $\mathbf{2 2}$ & $\mathbf{1 . 2 7 6 7 5}$ & & & \\
\hline
\end{tabular}

\section{CONFIRMATION EXPERIMENTS}

\section{For MRR \& SR}

Table 10 represents the confirmation test for MRR and SR. In the present case, confirmation experiment was required because, the optimal solution for factors and their levels are not matched with experiments of orthogonal array (L18). Like for present case, optimal solution was at A2-B3-C2-D1-E3-F1for MRR and for SROptimal solution was at A1B3-C3-D1-E1-F1. 
So, same experiment (on optimal solution) was required to perform on the same machine (WEDM) to find MRR and SR, for this, optimal solution and then comparison with an estimated value was done, which ispresented in table 10.

$$
\begin{aligned}
& \text { MRR }=1.05+0.155 \text { Tool Electrode }+0.0831 \text { Current }+0.01031 \text { Ton }-0.0030 \text { Toff }+0.0531 \mathrm{WF}-0.0133 \mathrm{WT} \\
& \mathbf{S R}=4.043+0.1356 \text { Tool Electrode }-0.0653 \text { Current }-0.01467 \text { Ton }+0.02079 \text { Toff }+0.0522 \mathrm{WF}+0.0386 \mathrm{WT}
\end{aligned}
$$

Table 10: Confirmation Table for MRR and SR

\begin{tabular}{|l|c|c|c|c|}
\hline \multirow{2}{*}{ Level } & \multicolumn{2}{|c|}{ Optimal Solution } & \multirow{2}{*}{ Difference } & \multirow{2}{*}{ \% Diff } \\
\cline { 2 - 5 } & Estimated & Experiment & & \\
\hline A2-B3-C2-D1-E3-F1(MRR) & 3.89 & 3.56 & 0.33 & 8.48 \\
\hline A1-B3-C3-D1-E1-F1 (SR) & 3.06 & 2.71 & 0.35 & 11.43 \\
\hline
\end{tabular}

\section{CONCLUSIONS}

In current work, WEDM with cryogenic treated tool electrode has been successfully performed on incognel-625 work piece material. The effect of process parameters that is tool electrode (plain and cryogenic), current, Ton, Toff, wire feed and wire tension on responses, that is MRRand SR has been investigated. Following are the conclusions:

- Results show that cryogenic tool electrode, pulse on time, wire feed and pulse off time are significant parameters for MRR and SR. Wire tension does not show any major effect on the process parameters.

- Experimental study shows that for MRR, A2-B3-C2-D1-E3-F1are the optimal values, which gives the better results. For SR, A1-B3-C3-D1-E1-F1is the optimal value, which gives the better results. The improved MRR and SR were $8.48 \%$ and $11.43 \%$, respectively based on optimal setting of input parameters for responses, MRR and $\mathrm{SR}$, lies between the calculated confidence interval.

- Regression equation has been effectedand found to develop the mathematical models for process parameters, and confirmation test has been performed for validation of results.

- In the future, the work can be extended to the discussion of the wire wear rate, dimensional accuracy, and surface integrity of other heat treatment process during machining of the other tool electrode and advanced material by different non-conventional machining techniques.

\section{ACKNOWLEDGEMENTS}

The authors would like to accept the monetary support of Manipal University, Jaipur, grant no. order MUJ/REGR/1403/11. Furthermore, we would like to thank CIPET Ahmedabad for providing surface roughness testing facility and Material Research Centre, MNIT Jaipur for carried out Material characterization. 


\section{REFERENCES}

1. Ahsan Ali Khanet al, "Improving tool life using cryogenic cooling", Journal of materials processing technology volume 196 Issues 1-3, Pages 149-154 (2008)

2. Paolo Baldissera et al, "Effects of deep cryogenic treatment on static mechanical properties of 18 nicrmo5 carburized steel", Volume 30, Issue 5, Pages 1435-1440 (2008)

3. J. M. Jafferson et al, "Machining performance of cryogenically treated electrodes in micro electric discharge machining: a comparative experimental study”, Journal of Materials and Manufacturing processes, volume 28, Issue-4 (2013)

4. D. Senthilkumar et al, "Optimization of deep cryogenic treatment to reduce wear loss of 4140 steel", Materials and Manufacturing Processes, Journal of Materials and Manufacturing processes, volume 27, Issue-5 (2012)

5. Yildiz, $Y$ et al., "The effects of cold and cryogenic treatments on the machinability of beryllium-copper alloy in electro discharge machining”, Industrial and Management Systems Engineering,(2011)

6. Shane Y. Hong et al "New cooling approach and tool life improvement in cryogenic machining of titanium alloy Ti-6Al-4V", International Journal of Machine Tools \& Manufacture, Pages 2245-2260, Volume 41, Issue 15, (2001)

7. Vineet Srivastava et al, "Study of ultrasonic assisted cryogenically cooled EDM process using sintered (Cu-TiC) tooltip", Journal of Manufacturing Processes, Pages 158-166 Volume 15, Issue (2013)

8. Vinoth Kumar. S et al, "Optimization of cryogenic cooled EDM process parameters using grey relational analysis", Journal of Mechanical Science and Technology, Volume 28, Issue 9, pp 3777-3784, DOI 10.1007/s12206-014-0840-9 (2014)

9. A.B.Puri, B.Bhattacharya, "An analysis and optimisation of the geometrical inaccuracy due to wire lag phenomenon in WEDM”, International Journal of Machine Tools \& Manufacture, Pages 151-159, Volume 43, Issue 2, (2003)

10. O.Belgassim, et al "Investigation of the influence of EDM parameters on the overcut for AISI D3 tool steel", DOI: $10.1177 / 0954405411400498(2011)$

11. U.A.Dabade, et al, "Analysis of response variables in WEDM of Inconel 718 using Taguchi technique", Procedia CIRP, Pages 886-891, Volume 41, 2016 (2016)

12. G Selvakumar et al, "Experimental investigation on die corner accuracy of wire electrical discharge machining of Monel 400 alloy”, DOI: 10.1177/0954405412456660, (2012)

13. Sourabh.K.Saha, S.K. Choudhury, "Experimental investigation and empirical modeling of the dry electric discharge machining process", International Journal of Machine Tools and Manufacture, Pages 297-308, Volume 49, Issues 3-4, March 2009 (2009)

14. AhsanAli Khan, Munitabt.Mohd Ali, Norhashimah Bt. MohdShaffiar, "Relationship of Roughness with Current and Voltage During WEDM", Journal of Applied Sciences, (2006)

15. M. Manjaiah, Rudolph F. Laubscher, Anil Kumar, S. Basavarajappa, "Parametric optimization of MRR and surface roughness in wire electro discharge machining (WEDM) of D2 steel using Taguchi-based utility approach”, DOI 10.1186/s40712-016-0060-4, (2016)

16. Harpreet Singh, Amandeep Singh, "Effect of Pulse ON/ Pulse Off time on machining of AISID3 die steel using copper and brass Electrode in EDM", International Journal of Engineering and Science, ISSN:2278-24721, Vol.1, Issue 9, PP 19-22 (2012) 